\title{
An innovative approach to the study of the model of a medical institution
}

\author{
Tatiana Grober ${ }^{1, *}$, Oleg Grober ${ }^{1}$, and Olga Savchenko ${ }^{1}$ \\ ${ }^{1}$ Don state technical University, Gagarin square, 1, Rostov-on-Don, 344003, Russia
}

\begin{abstract}
The majority of municipal medical institutions are not working effectively enough. Long waiting in the queue to see a doctor is one of the most significant problem of the organization in the field of healthcare. The SADT (Structured Analysis and Design Technique) methodology was used to find out the problems of functioning of the medical center. Functional diagrams of the subject area were constructed, which helped to understand how individual business processes of the organization that need to be optimized are implemented. A simulation model of the medical center "Detstvo+" in the GPSS World programming language has been developed. it is an open Queuing network consisting of 5 large nodes that are Queuing systems, which allows us to imagine the process of functioning of the medical center. The model was optimized according to the efficiency criterion of this system: while maintaining the volume of the incoming flow of applications, the number of rejections is kept to a minimum, while it is necessary to reduce the length of queues for doctor appointments. This model can also be used by institutions with a similar organizational structure to improve their systems and make management decisions.
\end{abstract}

\section{Introduction}

Medical centers are a fairly complex organization that has many different divisions, so it is impossible to model the process of the organization without the use of information technology.

When studying complex systems, models are constructed using the terminology of a certain mathematical theory, aiming to obtain functional dependencies of the characteristics of the system under study on the parameters.

Using simulation methods, you can create models of real systems "AS - IS" and conduct experiments without interfering with their operation, evaluate the impact of parameters that affect the characteristics of the model, find the advantages and disadvantages of the proposed changes, predict the behavior of the system, and compare various design options without the high cost of large-scale experiments.

In the scientific literature, such studies have been conducted in the 80 's of the 20th century. Recent work on the systematization of existing knowledge.

"Correspondingauthor: grober71@mail.ru 
It is quite popular to use simulation methods for solving logistics problems [1, 2], production systems [3], cloud technologies in simulation research [4] and routing flows in generalized queuing networks [5].

There are three main and most important simulation methods: discrete event modeling [6-9], agent modeling [10-12], and system dynamics [13-15]. To study a particular system, the researcher determines which method to use.

The task of finding optimal management of a medical facility using simulation methods is relevant. When using simulation modeling, you can conduct experiments and analyze the behavior of the system without interfering with the work of a real organization. As a result, it is possible to eliminate the detected problems in order to improve the efficiency of the institution in question.

The study of processes occurring in discrete systems with stochastic functioning is carried out within the framework of Queuing theory. Many models of real systems are constructed on the basis of queueing models.

\section{Materials and methods}

Many medical organizations face the fact that there are more people who want to get to their service than they can accept. In order to receive as many people as possible, each doctor is allocated a fixed time to serve patients. People have different health problems and the allocated time interval is often not enough, so in polyclinics, especially municipal ones, there are often queues of patients to see a doctor. Older people are usually tolerant of this fact, but parents with young children are very dissatisfied with being in the queue. To receive all patients, doctors have to work quickly, which reduces the quality of service. Even if you have an appointment with a doctor in advance, you may be on the waiting list for an additional examination. Some institutions will arrange a record in this case, but then the diagnosis may take weeks, which is undesirable. This work is devoted to how to organize the work of a medical institution in order to eliminate internal queues that arise during the examination of patients.

The medical center "Detstvo+" was considered as a research object. The medical center provides a wide range of medical services in such specializations as pediatrics, neurology, dentistry, has a department of functional diagnostics, is equipped with modern medical equipment, and has a variety of different programs focused on the prevention and early diagnosis of diseases in children. It maintains a staff of specialists and provides patient reception by appointment.

Research problem:

- identify and analyze the business processes of a medical institution, based on the structural and functional methodology of SADT;

- develop a simulation model of a medical facility in GPSS World;

- identify problem areas in the activities of a medical organization;

- eliminate the detected problems in order to improve the efficiency of the institution in question.

Method of research.

The SADT (Structured Analysis and Design Techique) methodology was used to determine the business processes of a medical institution.

To build a model of the business process of patient care, the methodology of discrete event modeling was used. In order to develop a simulation model of a medical center, the most suitable GPSS World environment was selected for this purpose, which is intended for modeling Queuing systems and other similar systems. 


\section{Results}

In the beginning, the process of organizing patient care was considered from the point of view of the head of the medical center. The All Fusion Process Modeler environment was used as a tool for developing a functional model (IDEF0 - model). For a more detailed study of the process of patient care, diagrams of the decomposition of this process were constructed (Fig. 1). in order to eliminate the detected problems and improve the efficiency of the institution under consideration, a functional model of the "AS - IS" medical center was constructed. As a result, several so-called "bottlenecks" were found in the work of the medical center: the formation of queues and long stay in them in the departments of neurology and functional diagnostics. There are three types of patient requests: consultation; admission, additional examination, return to the doctor, diagnosis and appointment; repeat appointment.

The second type of application is of the greatest interest (consultation with a doctor at the reception, followed by an examination at the functional diagnostics department, thenreturn to the doctor at the reception for diagnosis), because it is when contacting the functional diagnostics department and when contacting the doctor again after the examination that queues can form. 


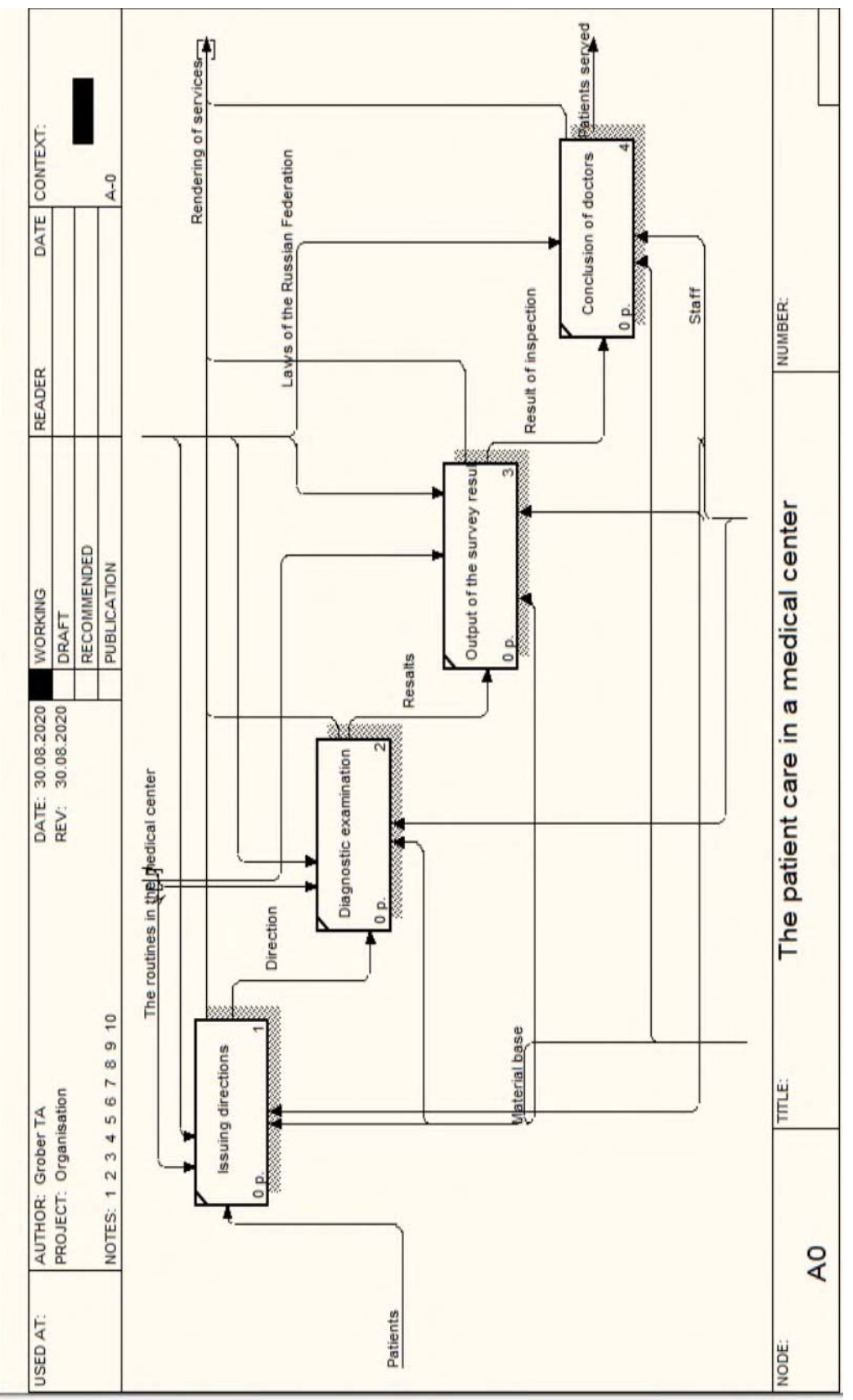

Fig. 1. Decomposition of the business process "Patient care in a medical center» Simulation model.

We represent the functioning of the medical center as an open Queuing network, which consists of 5 large nodes representing Queuing systems, contains eleven different queues, and patients are served by one of the employees of the Department where the application was received.

The main input parameters of the model: the number of patient requests, the number of employees of the medical center, the intervals of admission and patient care were similar to 
the average statistical indicators of previous periods of the center's operation. We believe that the time intervals between the receipt of applications (patients) to the registry have an even distribution in the interval $[2,4]$. The time of patient care in it is subject to a uniform distribution on average over the interval $[2,20]$. A simulation model of the functioning of a medical center during one working day was considered.

An open Queuing network has the following parameters: the number of servicing devices (doctors) - 12; the number of nodes (departments + registry) - 5; the storage capacity is unlimited; 3 types of requests, which form 9 streams (classes) of requests. The criterion for the effectiveness of this system is as follows: while maintaining the volume of the incoming flow of applications, the number of rejections is minimized, while it is necessary to reduce the length of queues for doctor appointments.

The graph of an open Queuing network will look as shown in fig. 2.

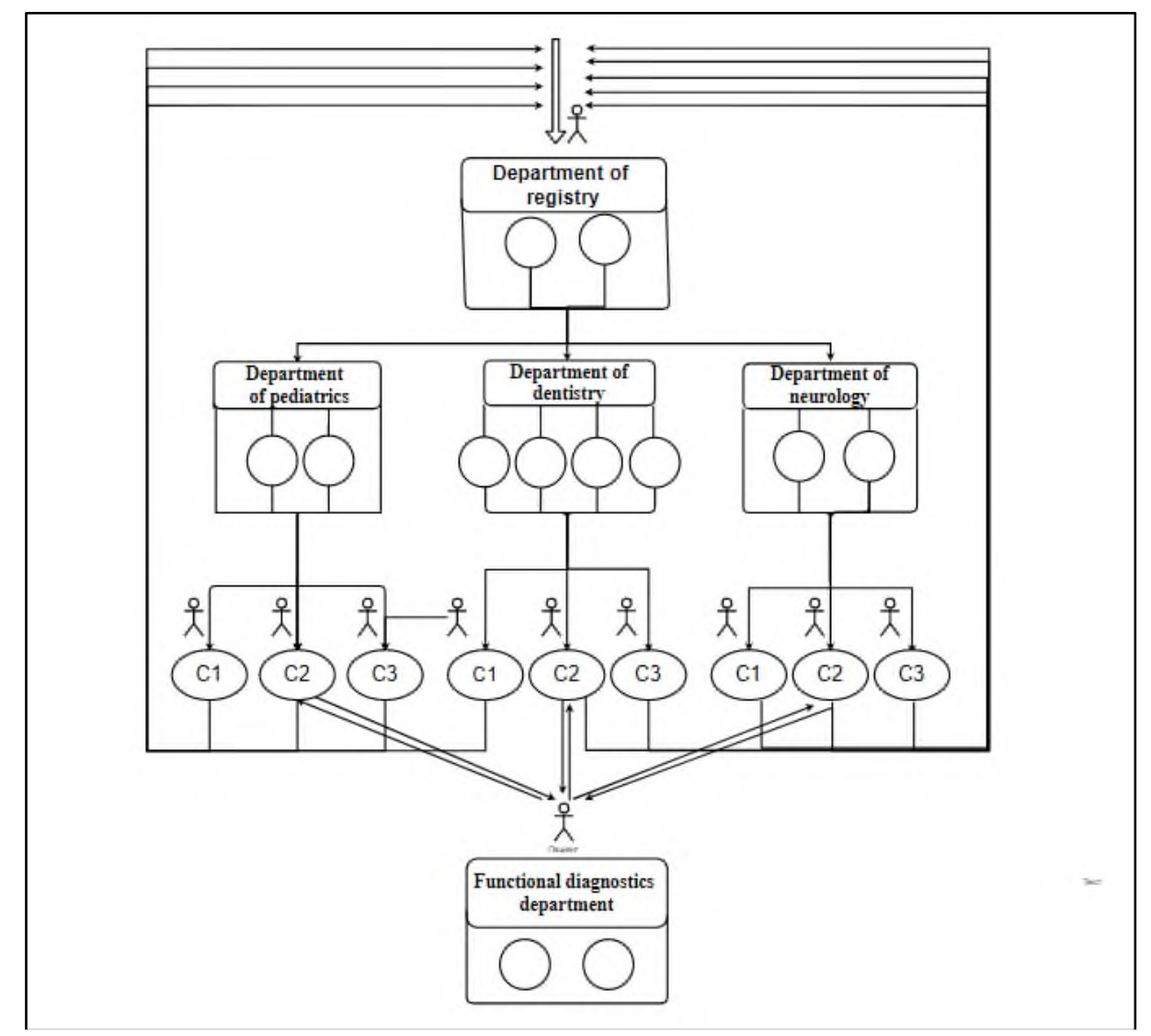

Fig. 2. Open Queuing network nraph

The process of functioning of the medical center is presented in more detail in fig. 3 . 


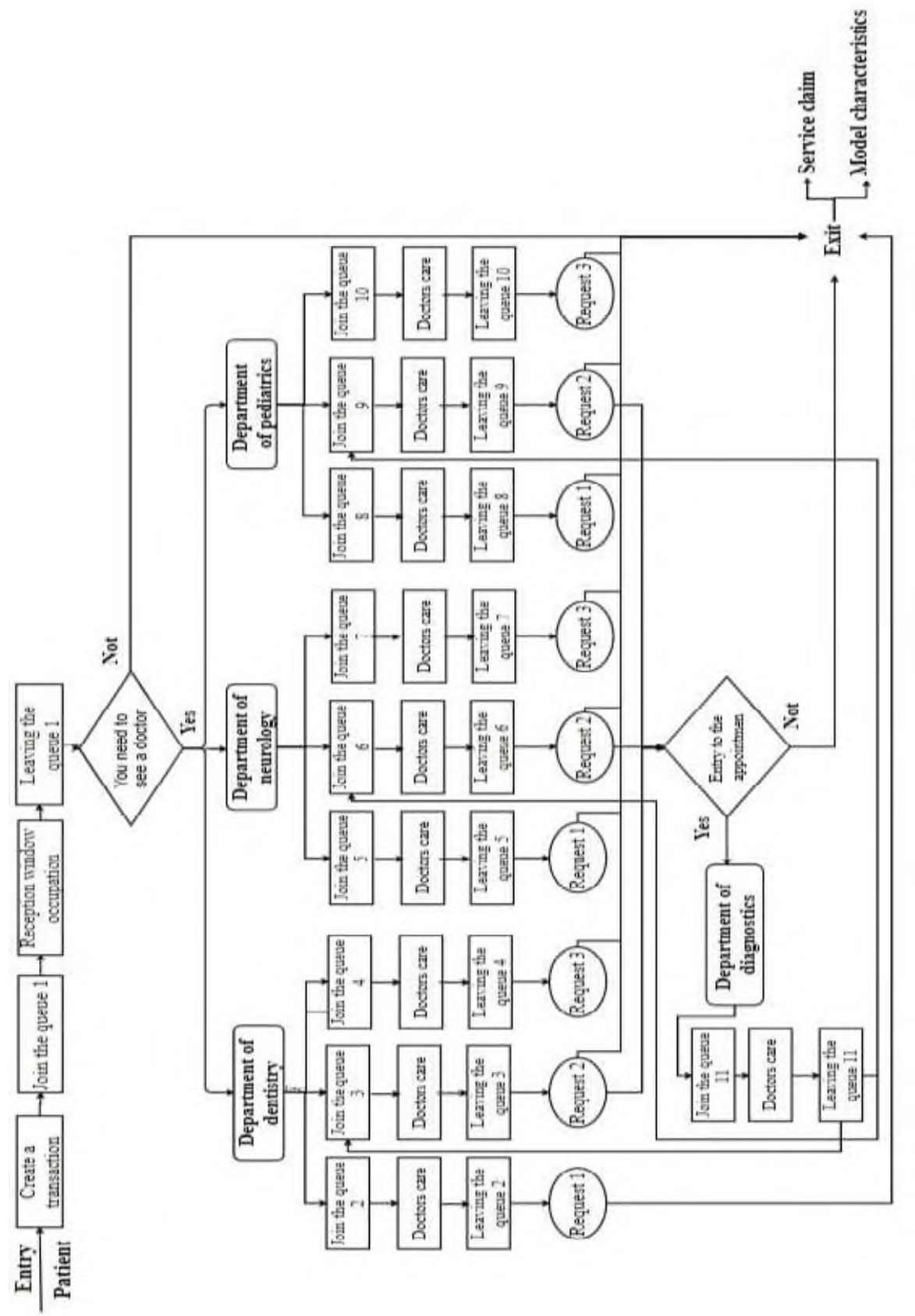

Fig. 3. Updated service scheme

After developing the model in GPSS and running the program, the following simulation report was received (fig. 4). 


\begin{tabular}{|c|c|c|c|c|c|c|c|c|c|c|c|c|}
\hline FACILITY & ENTRIES & \multicolumn{2}{|c|}{ UTIL. } & AVE. & TIME & \multicolumn{2}{|c|}{ AVAIL. } & DWNER & PEND & INTEP & ER RETRY & DELAY \\
\hline PERERIV_REG & 2 & 0.08 & & 20 & .000 & 1 & & 0 & 0 & 0 & 0 & 0 \\
\hline PERERIV_NEV & 2 & 0.12 & & 30 & .000 & 1 & & 0 & 0 & 0 & 0 & 0 \\
\hline PERERIV ST & 2 & 0.12 & & 30 & .000 & 1 & & 0 & 0 & 0 & 0 & 0 \\
\hline PERERIV_PD & 2 & 0.12 & & 30 & .000 & 1 & & 0 & 0 & 0 & 0 & 0 \\
\hline PERERIV_DG & 2 & 0.12 & & 30 & .000 & 1 & & 0 & 0 & 0 & 0 & 0 \\
\hline QUEUE & MAX C & CONT. & ENTRY & I ENT & $R Y(0)$ & AVE & . CONT. & $\therefore \mathrm{AVE}$ & E.TI & IME & AVE. $(-0)$ & RETRY \\
\hline QUE_REG & 1 & 0 & 153 & & 12 & 0. & 070 & & 0.22 & & 0.820 & 0 \\
\hline QUE_STOMATOLOGIYA_K1 & 1 & 0 & 8 & & 3 & 0. & 079 & & 4.72 & & 7.561 & 0 \\
\hline QUE_STOMATOLOGIYA-K2 & 3 & 0 & 36 & & 12 & 0. & 502 & & 6.68 & & 10.033 & 0 \\
\hline QUE_STOMATOLOGIYA_K3 & 2 & 0 & 40 & & 14 & 0. & 445 & & 5.34 & & 8.223 & 0 \\
\hline QUE_DIAGNOSTIKA & 6 & 2 & 35 & & 3 & 2. & 393 & & 2.82 & & 35.898 & 0 \\
\hline QUE_NEVROLOGIA_KI & 2 & 1 & 13 & & 3 & 0. & 608 & & 2.44 & & 29.180 & 0 \\
\hline QUE_NEVROLOGIA_K2 & 3 & 2 & 19 & & 0 & 0. & 997 & & 5.19 & & 25.199 & 0 \\
\hline QUE_NEVROLOGIA_K3 & 4 & 3 & 29 & & 5 & 1. & 424 & & 3.56 & & 28.471 & 0 \\
\hline QUE_PEDIATRIYA_K1 & 1 & 1 & 12 & & 4 & 0. & 132 & & 5.29 & & 7.937 & 0 \\
\hline QUE_PEDIATRIYA_K2 & 2 & 0 & 22 & & 9 & 0.2 & 293 & & 6.38 & & 10.805 & 0 \\
\hline QUE_PEDIATRIYA_K3 & 2 & 0 & 18 & & 6 & 0.2 & 254 & & 6.78 & & 10.176 & 0 \\
\hline STORAGE & CAP. & REM. & MIN. & MAX. & ENTF & RIES & AVL. & AVE & E.C. & . UTIL. & RETRY & DELAY \\
\hline STOMATOLOGIYA & 4 & 0 & 0 & 4 & & 84 & 1 & 3.44 & 49 & 0.862 & 0 & 0 \\
\hline NEVROLOGIA & 2 & 0 & 0 & 2 & & 55 & 1 & 1.76 & 62 & 0.881 & 0 & 6 \\
\hline PEDIATRIYA & 2 & 0 & 0 & 2 & & 51 & 1 & 1.62 & 26 & 0.813 & 0 & 1 \\
\hline DIAGNOSTIKA & 2 & 0 & 0 & 2 & & 33 & 1 & 1.76 & 61 & 0.881 & 0 & 2 \\
\hline REGISTR & 2 & 1 & 0 & 2 & & 53 & 1 & 1.55 & 57 & 0.779 & 0 & 0 \\
\hline
\end{tabular}

Fig. 4. Report on modeling the operation of a medical center

During one eight-hour working day, the reception served 153 applications, of which 112 requests with zero wait time, maximum queue length was 1 , the average time spent by patient in the queue is 0.22 , and the average time the patient is in a queue with zero timeout 0.82 .

In this model, the average number of medical center employees is $85 \%$, and the maximum queue length is not more than 6 , which indicates sufficient resource usage and not too long waiting time in the queue. Note that when modeling the work of employees, a 30 -minute lunch break was taken into account. However, it is impossible to say that this model meets the efficiency criterion, since it contains 9 failures, which means that one or more nodes of the Queuing network are overloaded. When a node is overloaded, the average time for requests to stay in the network is quite long.

During the simulation, the neurology Department received 19 requests of the second type for service, there were no requests with zero waiting time, the maximum length of the queue was 3 , the number of patients in the queue at the end of the simulation is 2 , the average time of the patient in the queue is 25.199 minutes, and the average time of the patient in the queue with zero waiting time is 25.199 minutes. The average time spent by a patient of the first type in the queue is 22.446 , and the average time spent by a patient in the queue with zero waiting time is 29.180 . For patients of the third type, this time is 23.562 and 28.471 minutes, respectively. The Department of neurology is one of the "bottlenecks" of this model. This network node is clearly overloaded and is not working efficiently.

In the Department of functional diagnostics during simulation the service received 35 applications, of which 3 with zero wait time, maximum queue length was 6 , the number of patients waiting at the end of the simulation is 2 , the average time spent by patient in the queue 32.821 , and the average time spent by patient in the queue with zero waiting time 35.898. This Department is very congested, according to the simulation data.

In order to get rid of the overload in the system, it is necessary to unload the "bottleneck". This can be achieved in several ways:

- increasing the operating speed of the service device;

- increasing the number of service devices; 
- reducing the probability of sending the request to the node.

Each of these methods will increase the performance of the system, as well as possibly increase the characteristics of the system.

The search for the optimal version of the model (corresponding to the efficiency criterion) was implemented on the basis of a simulation model of the functioning of the "TO-BE" medical center, some of the input parameters of which were changed.

In this model, the highest number of rejections is associated with the service of applications in the Department of neurology. Therefore, it is advisable to unload it. The second method was chosen for unloading, which resulted in an increase in the number of servicing devices by 1 unit.

Thus, a new simulation report was generated in accordance with fig. 5 (model 2).

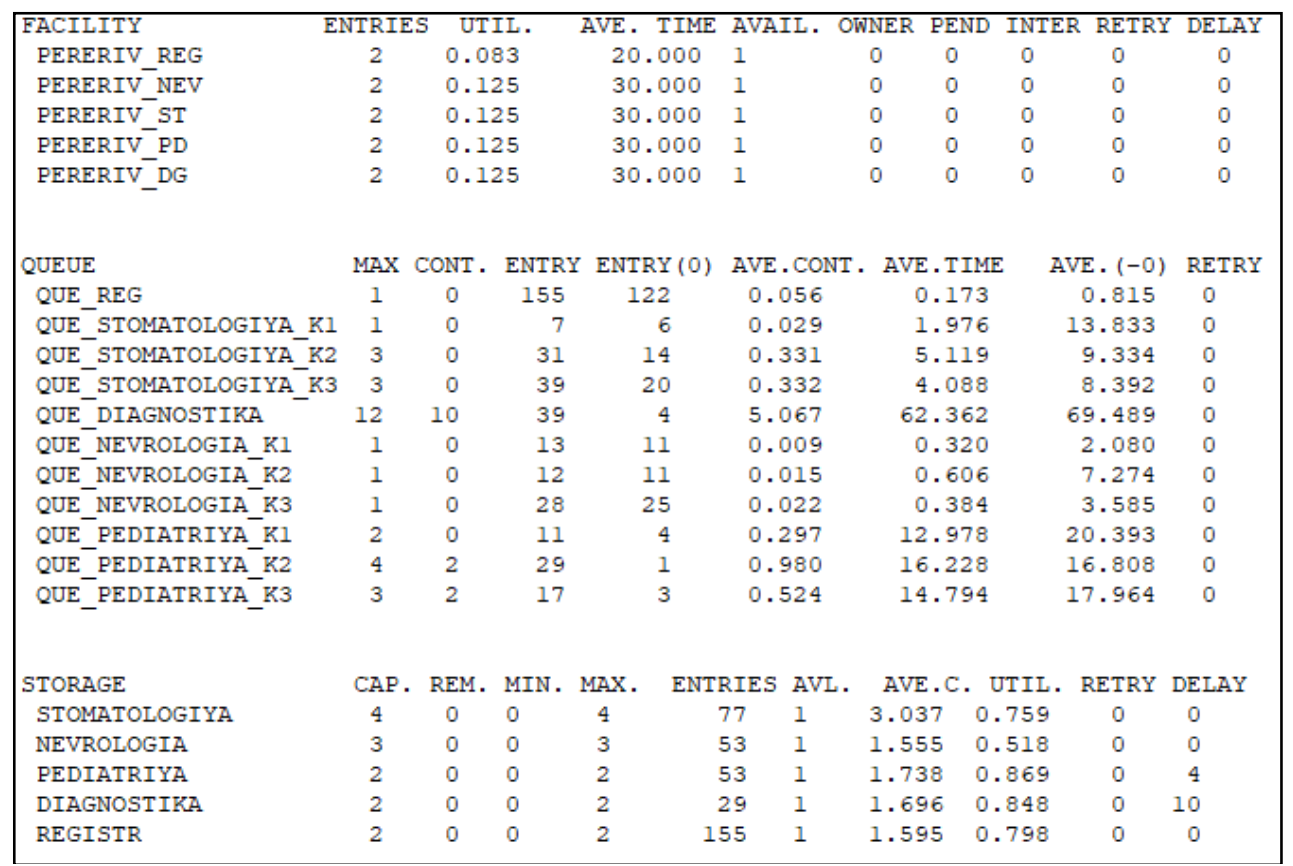

Fig. 5.Simulation report (model 2)

In order to estimate the utilization rate of service devices of this model, the values of the UTIL indicator were compared. After adding the number of service devices in the neurology department, the load factors of the Queuing network, as in the previous model, have good indicators in the range from 0.518 to 0.869 . Thus, in this model, the employees of the medical center are on average $70 \%$ employed.

Now, let's check whether this model has overloaded resources and evaluate its main characteristics. To do this, we will collect the necessary data in table 1.

Table 1. Analysis of the characteristics of the model 2

\begin{tabular}{|c|c|c|c|c|c|}
\hline Department name & $\begin{array}{c}\text { DELAY } \\
\text { (Number of } \\
\text { rejections) }\end{array}$ & $\begin{array}{c}\text { Time } \\
\text { spent in } \\
\text { the } \\
\text { queue }\end{array}$ & $\begin{array}{c}\text { Queue } \\
\text { length }\end{array}$ & $\begin{array}{c}\text { Number } \\
\text { of } \\
\text { entries }\end{array}$ & $\begin{array}{c}\text { MAX } \\
\text { queue }\end{array}$ \\
\hline REGISTRATURA & 0 & 0.173 & 0.059 & 155 & 1 \\
\hline STOMATOLOIYA K1 & 0 & 1.976 & 0.029 & 7 & 1 \\
\hline STOMATOLOIYA K2 & 0 & 5.119 & 0.331 & 31 & 3 \\
\hline STOMATOLOIYA K3 & 0 & 4.088 & 0.332 & 39 & 3 \\
\hline
\end{tabular}




\begin{tabular}{|l|l|l|l|l|l|}
\hline NEVROLOGIYA K1 & 0 & 0.320 & 0.009 & 13 & 1 \\
\hline NEVROLOGIYA K2 & 0 & 0.606 & 0.015 & 12 & 1 \\
\hline NEVROLOGIYA K3 & 0 & 0.384 & 0.022 & 28 & 1 \\
\hline PEDIATRIYA K1 & 0 & 12.978 & 0.297 & 11 & 2 \\
\hline PEDIATRIYA K2 & 2 & 16.228 & 0.980 & 29 & 4 \\
\hline PEDIATRIYA K3 & 2 & 14.794 & 0.524 & 17 & 3 \\
\hline DIAGNOSTIKA & 10 & 62.362 & 5.067 & 39 & 12 \\
\hline
\end{tabular}

Analyzing the data in table 1, we note that after adding the number of servicing devices in the neurology department, the model still has an overloaded node, namely, the functional diagnostics department (the waiting time in the queue was 62.362). Also, the number of rejections increased by 5 units, and the maximum queue length increased by 6 units.

Thus, this model does not meet the efficiency criterion, since it should not have such a long waiting time in the queue and congestion. Therefore, it was decided to unload the department of functional diagnostics in the same way. After that, the simulation report looks like this in accordance with fig. 6 (model 3).

\begin{tabular}{|c|c|c|c|c|c|c|c|c|c|c|c|c|}
\hline FACILITY & \multicolumn{2}{|c|}{ ENTRIES } & UTIL. & \multicolumn{4}{|c|}{ AVE. TIME AVAIL. } & \multirow{2}{*}{$\begin{array}{c}\text { OWNER } \\
0\end{array}$} & \multirow{2}{*}{$\begin{array}{l}\text { PEND } \\
0\end{array}$} & \multirow{2}{*}{$\begin{array}{l}\text { INTER } \\
0\end{array}$} & RETRY & DELAY \\
\hline PERERIV REG & 2 & 0.0 & & 20. & 000 & 1 & & & & & 0 & 0 \\
\hline PERERIV NEV & 2 & 0.1 & & 30 . & 000 & 1 & & 0 & 0 & 0 & 0 & 0 \\
\hline PERERIV_ST & 2 & 0.1 & & 30. & 000 & 1 & & 0 & 0 & 0 & 0 & 0 \\
\hline PERERIV ${ }^{-}$PD & 2 & 0.1 & & 30 . & 000 & 1 & & 0 & 0 & 0 & 0 & 0 \\
\hline PERERIV_DG & 2 & 0.1 & & 30 . & 000 & 1 & & 0 & 0 & 0 & 0 & 0 \\
\hline QUEUE & $\operatorname{Max}$ & CONT. & ENTRY & ENTR & $Y(0)$ & AVE & . CONT & C. AVE. & TIME & & AVE. $(-0)$ & RETRY \\
\hline QUE_REG & 2 & 0 & 159 & 10 & & & 131 & & 395 & & 1.184 & 0 \\
\hline QUE_STOMATOLOGIYA_KI & 1 & 0 & 7 & & 2 & & 062 & & 252 & & 5.952 & 0 \\
\hline QUE_STOMATOLOGIYA_K2 & 3 & 0 & 35 & & 8 & & 445 & & .098 & & 7.904 & 0 \\
\hline QUE_STOMATOLOGIYA_K3 & 3 & 2 & 50 & & 7 & & 685 & & 579 & & 7.650 & 0 \\
\hline QUE_DIAGNOSTIKA & 5 & 4 & 49 & 2 & 1 & & 588 & & .760 & & 10.079 & 0 \\
\hline QUE_NEVROLOGIA_K1 & 1 & 0 & 12 & 1 & 1 & & 006 & & 251 & & 3.009 & 0 \\
\hline QUE_NEVROLOGIA_K2 & 1 & 0 & 18 & 1 & 2 & & 041 & & 102 & & 3.307 & 0 \\
\hline QUE_NEVROLOGIA_K3 & 2 & 0 & 27 & 1 & 9 & & 073 & & 289 & & 4.350 & 0 \\
\hline QUE_PEDIATRIYA_KI & 1 & 0 & 10 & & 3 & & 206 & & 879 & & 14.112 & 0 \\
\hline QUE_PEDIATRIYA_K2 & 3 & 0 & 23 & & 3 & & 588 & 12. & 277 & & 14.119 & 0 \\
\hline QUE_PEDIATRIYA_K3 & 2 & 0 & 21 & & 3 & & 555 & 12. & 689 & & 14.804 & 0 \\
\hline STORAGE & CAP. & REM. & MIN. & MAX. & ENT: & RIES & AVL. & AVE. & C. UT & IIL. & RETRY & DELAY \\
\hline STOMATOLOGIYA & 4 & 0 & 0 & 4 & & 90 & 1 & 3.650 & 0.9 & 913 & 0 & 2 \\
\hline NEVROLOGIA & 3 & 1 & 0 & 3 & & 57 & 1 & 1.744 & 0.5 & 581 & 0 & 0 \\
\hline PEDIATRIYA & 2 & 0 & 0 & 2 & & 54 & 1 & 1.744 & 0.8 & 872 & 0 & 0 \\
\hline DIAGNOSTIKA & 4 & 0 & 0 & 4 & & 45 & 1 & 2.554 & 0.6 & 639 & 0 & 4 \\
\hline REGISTR & 2 & 0 & 0 & 2 & 1 & 59 & 1 & 1.665 & 0.8 & 833 & 0 & 0 \\
\hline
\end{tabular}

Fig. 6. Simulation report (model 3)

Note that in comparison with the previous model, the load factor in nodes where there were underloads increased, and where there were overloads - decreased, and they are in the range from 0.581 to 0.913 .

Now let's check whether this model has overloaded nodes and evaluate its main characteristics to do this, we will collect the necessary data in table 2.

Table 2. Analysis of model 3 characteristics

\begin{tabular}{|l|c|c|c|c|c|}
\hline Department name & $\begin{array}{c}\text { DELAY } \\
\text { (Number of } \\
\text { rejections) }\end{array}$ & $\begin{array}{c}\text { Time spent in } \\
\text { the queue }\end{array}$ & $\begin{array}{c}\text { Queue } \\
\text { length }\end{array}$ & $\begin{array}{c}\text { Number } \\
\text { of entries }\end{array}$ & $\begin{array}{c}\text { MAX } \\
\text { queue }\end{array}$ \\
\hline REGISTRATURA & 0 & 0.395 & 0.131 & 159 & 2 \\
\hline STOMATOLOIYA K1 & 0 & 4.252 & 0.062 & 7 & 1 \\
\hline
\end{tabular}




\begin{tabular}{|l|c|c|c|c|c|}
\hline STOMATOLOIYA K2 & 0 & 6.098 & 0.445 & 35 & 3 \\
\hline STOMATOLOIYA K3 & 2 & 6.579 & 0.685 & 50 & 3 \\
\hline NEVROLOGIYA K1 & 0 & 0.251 & 0.006 & 12 & 1 \\
\hline NEVROLOGIYA K2 & 0 & 1.102 & 0.041 & 18 & 1 \\
\hline NEVROLOGIYA K3 & 0 & 1.289 & 0.073 & 27 & 2 \\
\hline PEDIATRIYA K1 & 0 & 9.879 & 0.206 & 10 & 1 \\
\hline PEDIATRIYA K2 & 0 & 12.277 & 0.588 & 23 & 3 \\
\hline PEDIATRIYA K3 & 0 & 12.689 & 0.555 & 21 & 2 \\
\hline DIAGNOSTIKA & 4 & 5.760 & 0.588 & 49 & 5 \\
\hline
\end{tabular}

Based on the simulation results, we can say that the model does not have overloaded resources, because the waiting time in the queue is quite stable and does not exceed 15 minutes, which is considered acceptable, as a result, the length of queues has decreased, and the number of service failures has decreased to 6 units for the entire working day of the medical center.

Based on the results of the model study, the following main indicators of the Queuing network were collected in table 3 .

Table 3. Main characteristics of an open Queuing network

\begin{tabular}{|l|c|c|c|}
\hline \multicolumn{1}{|c|}{ Characteristic of model } & Model 1 & Model 2 & Model 3 \\
\hline Load (average value) & 0.82 & 0,748 & 0.78 \\
\cline { 1 - 1 } Waiting time in the queue (average value) & 12.67 & 10.82 & 5.506 \\
\hline Queue length (average value) & 0.65 & 0.69 & 0.3 \\
\hline MAX queue (average value) & 2.45 & 2.9 & 2.18 \\
\hline Number of entries (average value) & 35 & 34.63 & 37.36 \\
\hline Number of rejections & 9 & 14 & 6 \\
\hline
\end{tabular}

According to the data from table 3, you can see that model 3 is the most relevant for a medical center, since only it meets the efficiency criterion: the number of failures is minimized, while the length of queues for doctor appointments is minimized. This model has the highest average number of applications served (37.36) among the considered options, which means that the medical center will serve the largest number of patients, which is confirmed by the report data.

For comparison, let's look at how the waiting time in the queue of the original model has changed compared to the optimized one, using the example of the queue in the functional diagnostics department on the corresponding histograms.

The waiting list for an appointment at the functional diagnostics department (initial model) has the following form in accordance with fig. 5. The horizontal axis shows the time intervals, and the vertical axis shows the number of patients. 


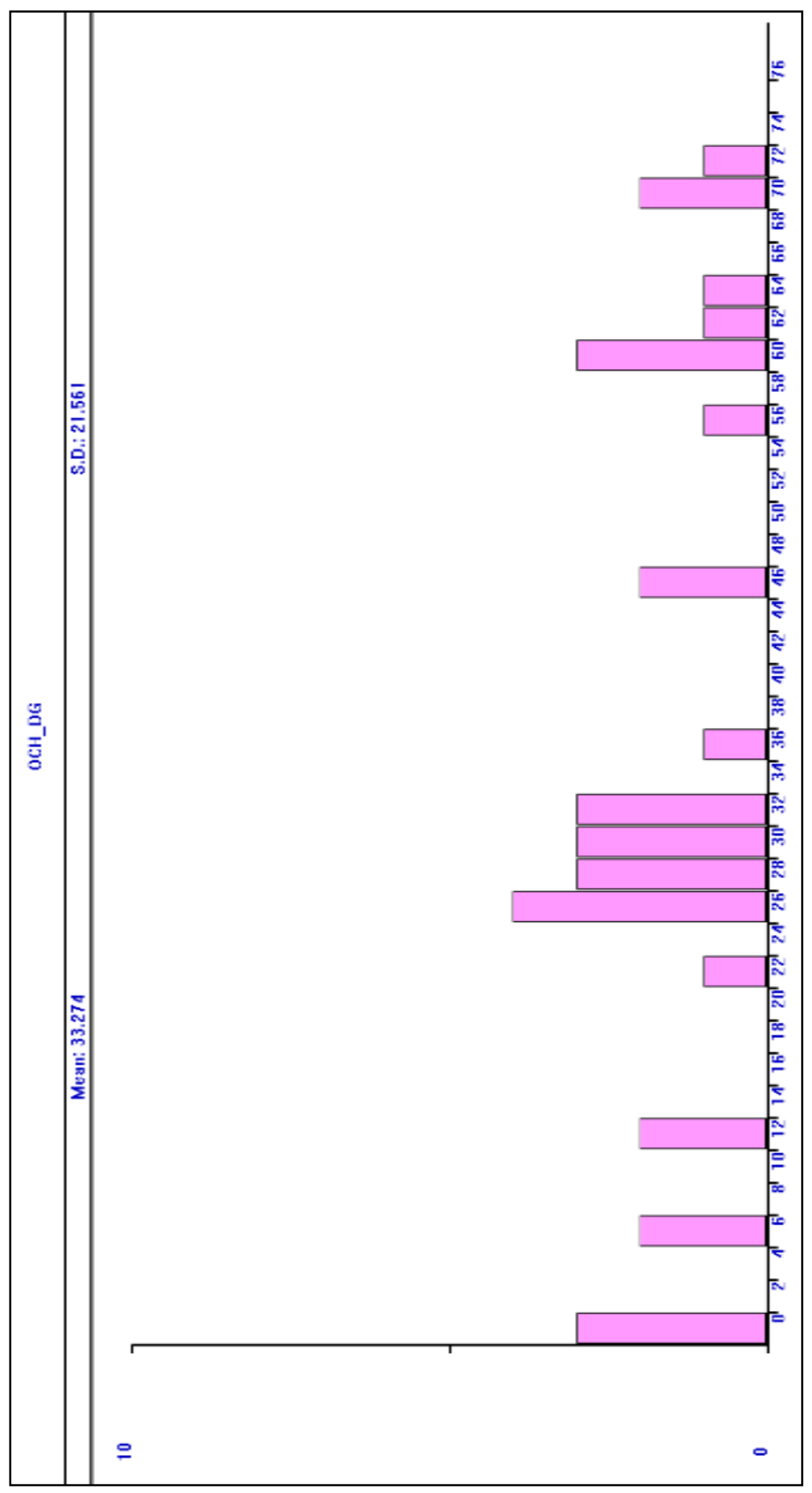

Fig. 7. Histogram describing the queue in the functional diagnostics department of the original model

The waiting list for an appointment in the department of functional diagnostics (optimized model) is shown in accordance with fig. 6. 


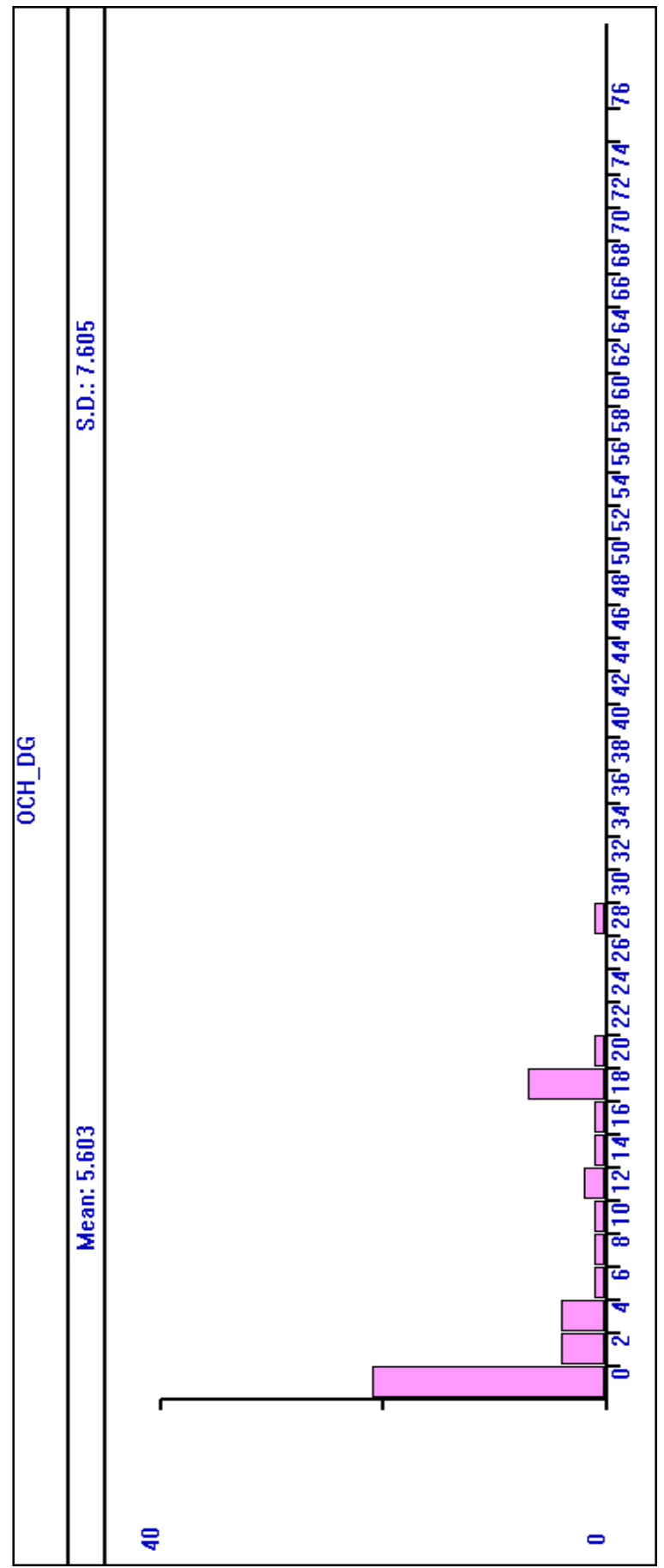

Fig. 8. Histogram describing the queue in the functional diagnostics Department of the optimized model

Analyzing figures 7 and 8, you can see that the number of patients in the waiting list has significantly decreased in the optimized model. 
Thus, we are once again convinced that the model 3 really meets all the requirements for system efficiency. The graph of the optimized model has the following form in accordance with fig. 9 .

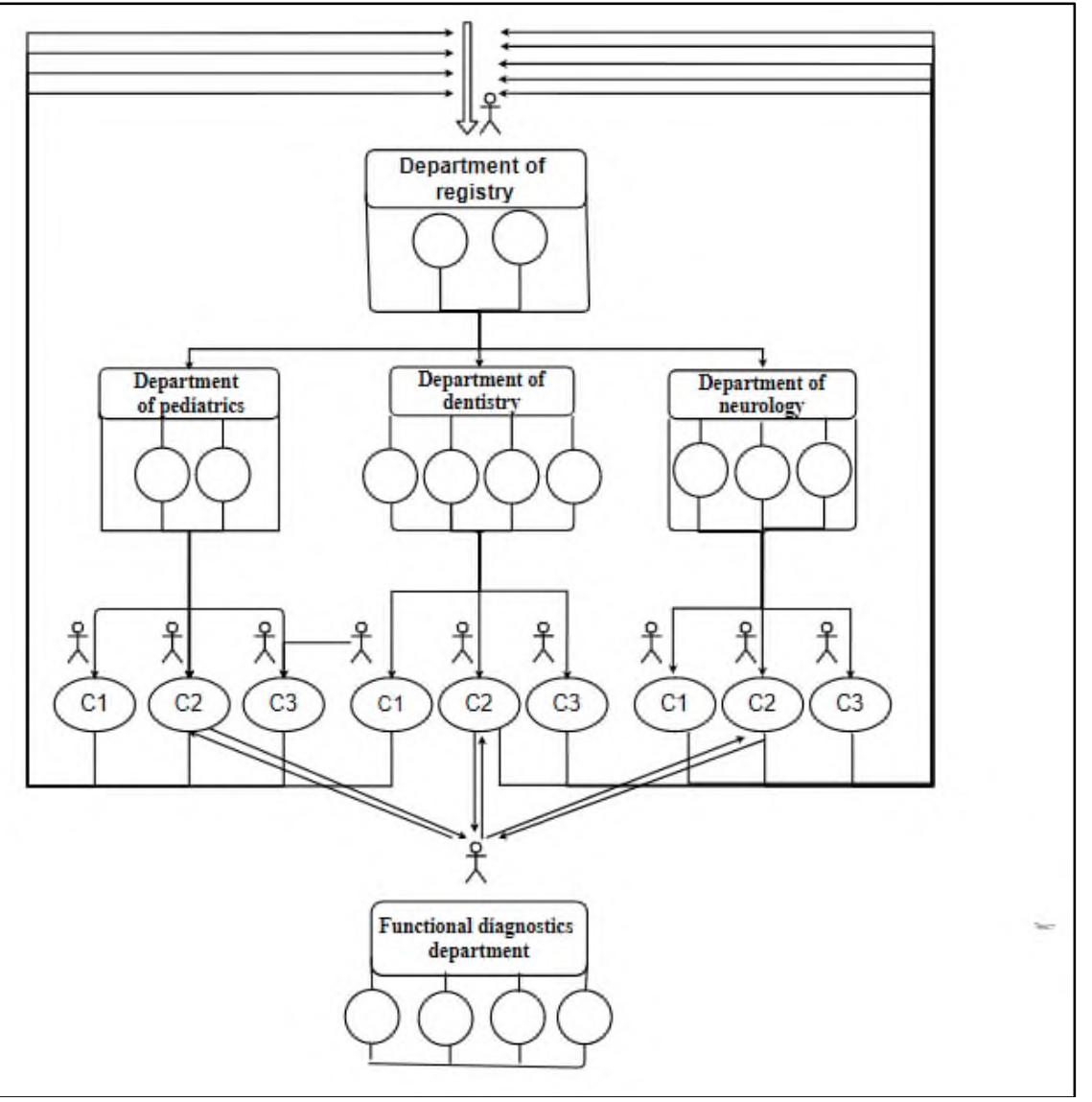

Fig. 9. Graph of an optimized open Queuing network

\section{Conclusions}

In this paper, the medical center management model was developed as a simulation model of an open Queuing network with a heterogeneous flow of applications and a relative priority of application service using the universal simulation environment GPSS World. It should be noted that the number of nodes in the model can be increased. This work allows us to solve a very important social problem - reducing internal queues in a medical facility, especially when it comes to children. The simulation model is an effective tool for operational management of medical institutions, helps the Manager to control business processes, predict the behavior of the model when changing input parameters, and form an optimal management strategy for the organization.

\section{References}

1. I. Bychkov, A. Feoktistov, O. Basharina, Procedia Engineering, 201, 524-533 (2017)

2. M. Kostrzewski, Procedia Engineering, 12, 445-450 (2017) 
3. K. David Strang, European Journal of Operational Research, 218(216), 493-504, (2012)

4. S. A. Vlasov, T. V. Devyatkov, V. V. Devyatkov, IFAC Proceedings Volumes, 46(9), 637-641 (2013)

5. R. Morabito, M. C. de Souza, M. Vazquez, European Journal of Operational Research, 232(31), 618-629 (2014)

6. B. P. Zeigler, A. Muzy, IFAC-Papers On Line, 50(1), 3039-3044 (2017)

7. A. P. G. Scheidegger, T. F. Pereira, M. L. M. de Oliveira, A. Banerjee, J. Arnaldo B. Montevechi, Computers \& Industrial Engineering, 124, 474-492 (2018)

8. E. Tarshizi, J. Sturgul, V. Ibarra, D. Taylor, International Journal of Mining Science and Technology, 25(4), 671-674 (2015)

9. S. Ďutková, K. Achimský, D. Hoštáková, Transportation Research Procedia, 40, 1037-1044 (2019)

10. Y. Liu, W. Wang, H.-Z. Huang, Y. Li, Y. Yang, Reliability Engineering \& System Safety, 121, 187-197 (2014)

11. J. A. García-Grcía, J. G. Enríquez, M. Ruiz, C. Arévalo, A. Jiménez-Ramírez, Computer Standards \& Interfaces, 70, 103425 (2020)

12. S. Alodhaibi, R. L. Burdett, P. Yarlagadda, Procedia Engineering, 174, 1100-1109 (2017)

13. G. Guizzi, D. Falcone, F. De Felice, Computers \& Industrial Engineering, 137, 106052, (2019)

14. Yi Xie, Chen-Fu Chien, Ren-Zhong Tang, Computers \& Industrial Engineering. 99, 401-414, (2016)

15. F. Yang, J. Liu, European Journal of Operational Research, 223(116), 150-166 (2012) 